\title{
Soft anatomy of the Early Cambrian arthropod Isoxys curvirostratus from the Chengjiang biota of South China with a discussion on the origination of great appendages
}

\author{
Dong-Jing Fu, Xing-Liang Zhang, and De-Gan Shu \\ Acta Palaeontologica Polonica 56 (4), 2011: 843-852 doi: http://dx.doi.org/10.4202/app.2010.0090
}

An updated reconstruction of the body plan, functional morphology and lifestyle of the arthropod Isoxys curvirostratus is proposed, based on new fossil specimens with preserved soft anatomy found in several localities of the Lower Cambrian Chengjiang Lagerstätte. The animal was $2-4 \mathrm{~cm}$ long and mostly encased in a single carapace which is folded dorsally without an articulated hinge. The attachment of the body to the exoskeleton was probably cephalic and apparently lacked any well-developed adductor muscle system. Large stalked eyes with the eye sphere consisting of two layers (as corneal and rhabdomeric structures) protrude beyond the anterior margin of the carapace. This feature, together with a pair of frontal appendages with five podomeres that each bear a stout spiny outgrowth, suggests it was raptorial. The following 14 pairs of limbs are biramous and uniform in shape. The slim endopod is composed of more than 7 podomeres without terminal claw and the paddle shaped exopod is fringed with at least 17 imbricated gill lamellae along its posterior margin. The design of exopod in association with the inner vascular (respiratory) surface of the carapace indicates I. curvirostratus was an active swimmer. Morphological comparisons demonstrate that species of Isoxys were diverse in feeding habits and occupied a very broad morphospace, i.e., carapace bivalved or a single shield, the pre-oral limbs antenniform or modified into great appendages, the succeeding endopods slim or stout. This casts doubt on the current taxonomy that assigns all species to a single genus, and on any presumed lifestyle of Isoxys extrapolated to the generic level. Finally, since I. curvirostratus and I. acutangulus carry a pair of great appendages, Isoxys has recently been placed into the great appendage arthropods. Such placement might be inadequate because the homology of the great appendages can not be established.

Key words: Arthropoda, Isoxys, soft anatomy, "great appendage", Chengjiang biota, Cambrian, China.

Dong-Jing Fu [eli djfu@yahoo.com.cn], Xing-Liang Zhang [xzhang69@nwu.edu.cn ], and De-Gan Shu [elidgshu@nwu.edu.cn], State Key Laboratory of Continental Dynamics, Early Life Institute and Department of Geology, Northwest University, Xian 710069, PR China. 
This is an open-access article distributed under the terms of the Creative Commons

Attribution License (for details please see creativecommons.org), which permits unrestricted use, distribution, and reproduction in any medium, provided the original author and source are credited.

Forif Full text $(1,404.0 \mathrm{kB})$ 